(1)

George Fox

UNIVERSITY
Digital Commons @ George Fox University

Faculty Publications - School of Physical

Therapy

School of Physical Therapy

2019

Does Physical Therapy Produce Value for Post-Operative and/or Non-Operative Foot and Ankle Patients?

Jeff Houck

Christopher Neville

Kostantinos Vasalos

Chad Condidorio

Kathleen Fear

See next page for additional authors

Follow this and additional works at: https://digitalcommons.georgefox.edu/pt_fac

Part of the Physical Therapy Commons 
Authors

Jeff Houck, Christopher Neville, Kostantinos Vasalos, Chad Condidorio, Kathleen Fear, and Judith F. Baumhauer 


\section{Does Physical Therapy Produce Value for Post-Operative and/or Non-Operative Foot and Ankle Patients?}

Jeff Houck, PT, PhD, Christopher Neville, PT, PhD, Kostantinos Vasalos, DPT, Chad Condidorio, DPT, Kathleen Fear, PhD, Judith F. Baumhauer, MD, MPH

\section{Category: Outcomes}

Keywords: Physical Therapy, Patient Reported Outcomes, Rehabilitation

Introduction/Purpose: Healthcare is at a unique time in history where patient reported outcomes have become important in assessing value and subsequent reimbursement with pay-4-performance initiatives. It is unclear whether physical function, pain and depressive symptoms can assist providers determine if additional physical therapy may improve care for foot and ankle patients considering post-op and/or non-operative care. The purpose of this research was to examine symptom severity (PROMIS PF, PI, and Dep) after surgery or with non-operative care at the start of formal physical therapy to determine if this symptom severity presentation and/or change in symptoms over time are predictors of improvement in physical function as assessed by PROMIS PF.

Methods: PROMIS scales were available at the start and end of physical therapy treatment for 377 patients with foot and ankle ICDI 0 codes. The mean age (40.2 \pm I8. I years), body mass index (BMI) $(28.9 \pm 7.9 \mathrm{~kg} / \mathrm{m} 2)$, and proportion of females $(62.1 \%)$ were recorded. The median number of physical therapy visits was 5 (interquartile range=5). Clinical categories of greater than 20 were identified for 7 groups including: Achilles rupture $(n=24)$, Fracture $(n=34)$, Ankle Pain $(n=105)$, Foot Pain ( $n=50)$, Ankle Sprain $(n=51)$, Achilles Non-Rupture $(n=45)$ and Other $(n=68)$. Two multivariate linear regression models; I) solely using data available at the start of therapy (age, gender, BMI, diagnosis category, PROMIS scores at the start of physical therapy); And, 2) a second model adding change in PROMIS PI, DP and completed visits to model I were examined for their ability to predict change in PF (Start to end of physical therapy).

Results: The average change in PROMIS PF was $6.5 \pm 8.8$ with a range of -20 to 49 .I. Correlations of PROMIS scales at the start of therapy with change in PROMIS PF were $r$-values $<0.48$. Correlations among change in PROMIS PI and Dep with PF scales were $r$ values $<0.38$. The first model predicting change in PF based on available data at the start of physical therapy included PROMIS $\operatorname{PF}(p<0.01), \operatorname{PI}(p<0.01)$ and $\operatorname{Dep}(p=0.03)$ at the start of physical therapy $(r$-value $=0.58$ an $r$-value increase of 0.1 over univariate correlations). No other variables were significant. The second model included $\operatorname{PROMIS~} P F(P<0.0 \mathrm{I}), \operatorname{PI}(p<0.0 \mathrm{I})$ and $\mathrm{Dep}(\mathrm{P}=0.05)$ and change in $\mathrm{PI}(\mathrm{p}<0.0 \mathrm{I})$, Dep $(\mathrm{p}=0.0 \mathrm{I})$ and visits completed $(\mathrm{p}<0.0 \mathrm{I})$ achieving an $r$-value $=0.75$ (an $r$-value increase of 0.27 over univariate values) (Figure I).

Conclusion: Providers should consider patients who present with more severe symptoms as good candidates for formal physical therapy. Positive trends during therapy suggest that patient may continue to improve. Severity of PI and Dep at the start of PT were independent predictors of improvements in PF. Using PROMIS assessments, appropriate referrals can be made to physical therapy to improve physical function and add value to the health of our patients. 


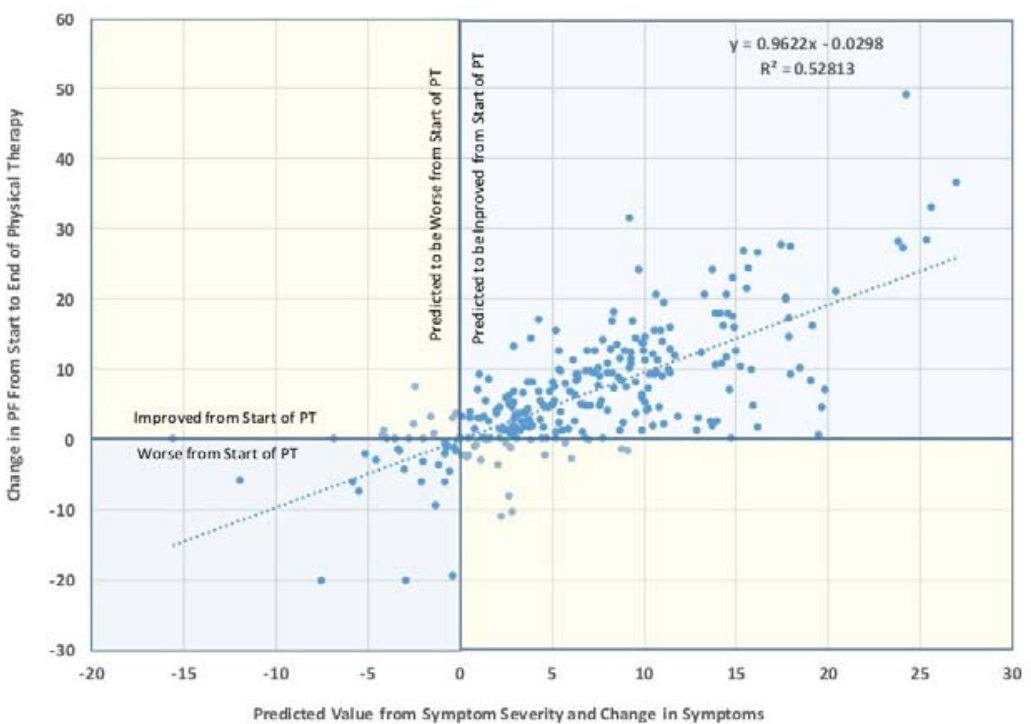

Figure 1. The predicted change in patient reported outcome information system(PROMIS) physical function (PF) scores based on the regression equation for variables available at the start of physical therapy (start PROMIS PF, pain interference (PI), and depression(Dep)) and response during physical therapy (change in $\mathrm{PI}$ and Dep) and number of completed visits ( $\mathrm{x}$-axis) compared to the actual change observed (y-axis).

Foot \& Ankle Orthopaedics, 4(4)

DOI: $10.1177 / 2473011419500033$

CThe Author(s) 2019 